\title{
Timing matters: Sensitivity of Daphnia magna dormant eggs to fenoxycarb exposure depends on embryonic developmental stage
}

\author{
Sabine Navis ${ }^{\mathrm{a}, *}$, Aline Waterkeyn $^{\mathrm{a}}$, Adinda Putman ${ }^{\mathrm{a}}$, Luc De Meester ${ }^{\mathrm{a}}$, \\ Guido Vanermen ${ }^{\mathrm{b}}$, Luc Brendonck ${ }^{\mathrm{a}}$ \\ a Laboratory of Aquatic Ecology, Evolution and Conservation, University of Leuven, Charles Deberiotstraat 32, 3000 Leuven, Belgium \\ ${ }^{\mathrm{b}}$ Flemish Institute for Technological Research (VITO NV), Unit Separation and Conversion Technology, Boeretang 200, 2400 Mol, Belgium
}

\section{A R T I C L E I N F O}

\section{Article history:}

Received 10 October 2014

Received in revised form

12 December 2014

Accepted 17 December 2014

Available online 19 December 2014

\section{Keywords:}

Resting egg bank

Ephippia

Embryo toxicity

Crustaceans

Insecticide

Bioaccumulation

\begin{abstract}
A B S T R A C T
Although Daphnia magna is a key species in many lentic freshwater ecosystems and is commonly used as model organism in ecology and ecotoxicology, very little is known about the effects of chemicals on their dormant life stages. Dormant eggs (ephippia) are produced when environmental conditions deteriorate, and Daphnia switch from clonal to sexual reproduction. Ephippia produced over different growing seasons can accumulate in the sediment of ponds and lakes, where they can be exposed to pesticides and other (anthropogenic) stressors. In the present study, we have investigated the effects of pesticide exposure on dormant eggs at different embryonic developmental stages and evaluated the degree of protection against pollution provided by the ephippial case. We therefore conducted a hatching experiment in which decapsulated and encapsulated dormant eggs were exposed to an insect growth regulator (fenoxycarb) at different stages during their development, both before and after activation of the eggs. In addition, we developed an analytical method to measure fenoxycarb concentrations in the dormant eggs. Fenoxycarb negatively affected development and hatching success and changed the timing of hatching in activated and in dormant eggs. Hatching characteristics as well as fenoxycarb concentrations inside the eggs differed significantly between exposure treatments. Final stages of embryonic development were most sensitive to pesticide exposure and had the highest tissue concentrations of fenoxycarb. Tissue concentrations did not differ significantly between decapsulated and encapsulated eggs, suggesting that the ephippial case offers limited or no direct protection against pesticide exposure. With this study we provide new evidence showing that pesticides can bioconcentrate in and affect $D$. magna dormant eggs. The severity of the effects on developing embryos depends on the timing of pesticide exposure. Our results stress the importance of considering the full life-cycle of model organisms used in ecotoxicological studies, since these are ultimately aimed at assessing risks of chemical exposure on natural aquatic ecosystems.
\end{abstract}

(c) 2014 Elsevier B.V. All rights reserved.

\section{Introduction}

Cyclical parthenogenesis is a mixed reproductive strategy, combining both sexual and asexual reproduction (Bulmer, 1982; De Meester et al., 2004). This strategy is especially common and well-studied in monogonont rotifers, aphids and cladocerans (Decaestecker et al., 2009). Like many other cladocerans, most Daphnia reproduce clonally under favorable environmental conditions, but switch to sexual reproduction when conditions deteriorate. Changes in, amongst others, oxygen level, food quantity and quality, photoperiod, temperature and predation can

\footnotetext{
* Corresponding author. Tel.: +32 (0)16 3245 69; fax: +32 (0)16 324575

E-mail address: Sabine.Navis@bio.kuleuven.be (S. Navis).
}

induce the production of males, which in turn fertilize sexual females, leading to the formation of dormant eggs (Alekseev and Lampert, 2001; Slusarczyk et al., 2005; Koch et al., 2009; Fig. 1A). Unlike parthenogenetic eggs, these dormant eggs have thick multilayered membranes (Seidman and Larsen, 1979; Zaffagnini, 1987; Fig. 1C) and are encapsulated in a protective structure, called ephippium (Schultz, 1977; Ebert, 2005; Fig. 1B), that protects them from mechanical damage and digestive enzymes of organisms like fish and birds (Mellors, 1975; Radzikowski, 2013). Dormant eggs can be dispersed to other water bodies or sink to the sediment layer, where they can remain viable for several decades to centuries (Frisch et al., 2014). Since only a fraction of the dormant eggs hatches each growing season, extensive mixed egg banks are build up over time, containing ephippia produced over different generations, thereby creating a buffering effect in terms of population dynamics and 


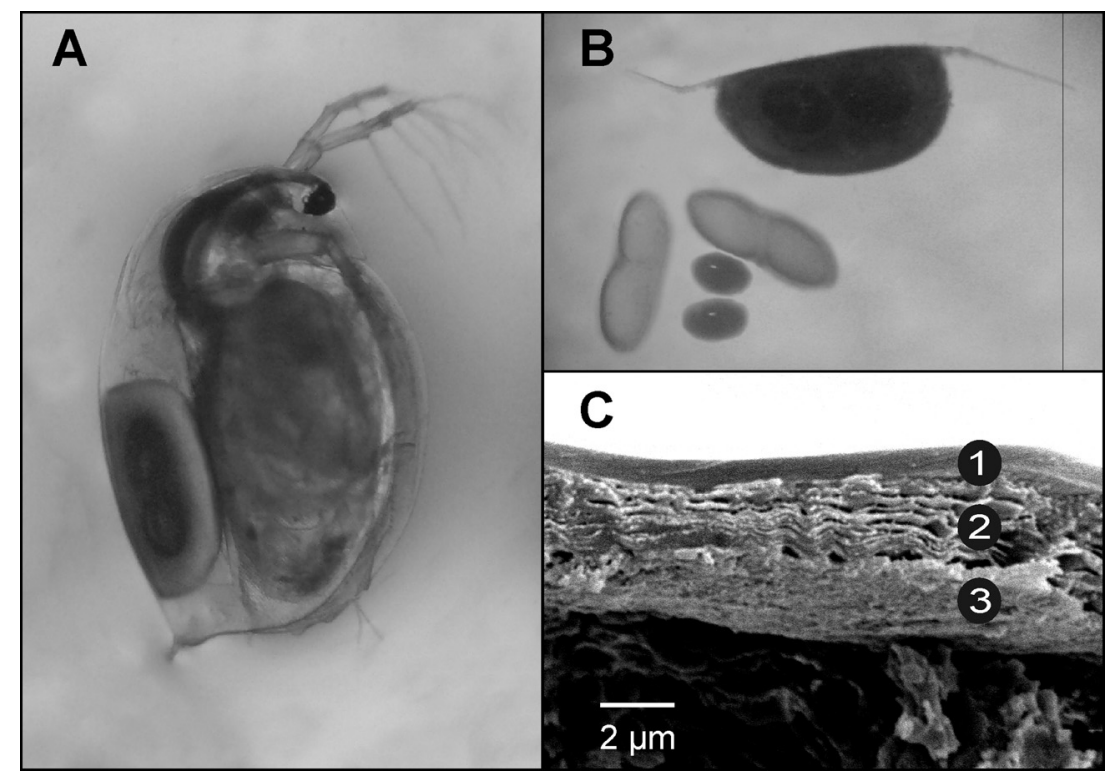

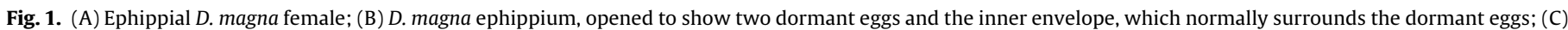
membrane structure of $D$. magna dormant egg (scanning electron microscope image): 1 = outer membrane; $2=$ middle membrane; $3=$ inner membrane.

genetic diversity (Caceres, 1997; Brendonck and De Meester, 2003; De Meester et al., 2006).

Daphnia plays a key role in many aquatic systems (Miner et al., 2012). It also is a well-established model organism in ecological and evolutionary research (Lampert and Kinne, 2011) and is used as standard test organism in ecotoxicology (Walker, 2014). Ecotoxicological studies using D. magna, performed according to internationally accepted guidelines (OECD TG 202, 2004; OECD TG 211,2012 ), generally focus on the effects of chemicals on the asexual part of the reproduction cycle, i.e. on clonal lineages consisting of genetically identical females. Despite its ecological importance, considerably less attention has been paid to the effects of chemicals on the sexual part of the reproduction cycle. Endpoints that could be affected by chemical exposure are: offspring sex ratio, dormant egg production and hatching success of dormant eggs. Of these, chemically induced production of male neonates has received increasing attention over the past years (Dodson et al., 1999; Olmstead and LeBlanc, 2003; Tatarazako and Oda, 2007; Palma et al., 2009). This resulted in the inclusion of offspring sex ratio as an additional optional endpoint in OECD TG 211 (OECD, 2012), mainly used to screen chemicals for potential endocrine disrupting effects. So far however, surprisingly little is known about effects of chemicals on the other two endpoints. Olmstead and LeBlanc (2001) have shown that methoprene, a juvenile hormone analog, is able to affect sexual reproduction in D. magna (male production was significantly delayed and increased, while dormant egg production was decreased). Also, the surfactant nonylphenol, has been shown to reduce the production of dormant eggs in $D$. magna (Shurin and Dodson, 1997). A few studies have tested the effects of organic chemicals on hatching of Daphnia dormant eggs: the fire retardant Fire-Trol ${ }^{\circledR} 934$ (Angeler et al., 2006), the insecticide fenoxycarb (Navis et al., 2013) and the biocides menadione and sodium hypochlorite (Raikow et al., 2006, 2007), have been shown to negatively affect dormant egg hatching success of $D$. curvirostris, $D$. magna and $D$. mendotae, respectively.

In the current study, we aim to expand our understanding of how and to which extent pesticides can affect development and hatching of $D$. magna dormant eggs, by determining the time window during which developing eggs are most sensitive to chemical exposure and by studying the protective value of the ephippial case. For this, we performed a hatching experiment, in which both decapsulated and encapsulated dormant eggs were exposed to the insect growth regulator fenoxycarb at different time periods during embryonic development, corresponding to different developmental stages (Fig. 2). In addition, we developed an analytical method that allows the measurement of fenoxycarb concentrations in the dormant eggs (Flemish Institute for Technological Research VITO $\mathrm{NV}$, Mol, Belgium). To the best of our knowledge, this is the first time that pesticide concentrations have been measured directly in the tissue of D. magna dormant eggs. Some earlier studies (Wyn et al., 2007; Chiaia-Hernandez et al., 2013) have measured toxicant levels in dormant stages of Daphnia, but using homogenized ephippia, i.e. including the eggs as well as the ephippial case. The concentrations reported could therefore include chemicals retained by the ephippial case and may not necessarily reflect concentrations of toxicants inside the eggs. We used our analytical method to detect whether tissue concentrations differed between treatments that were used in the hatching experiment. Our hypothesis was that the extent to which fenoxycarb penetrated the eggs would be related to effects on development and hatching, and would differ between developmental phases. The eggs were expected to be least sensitive to fenoxycarb exposure when they were still dormant (i.e. before hatching was initiated by light exposure), while later developmental stages were expected to be more sensitive.

\section{Materials and methods}

\subsection{Daphnia magna dormant eggs}

As starting material for the experiments, ephippia from Langerodevijver, a shallow lake situated in nature reserve "Doode Bemde" close to Leuven (Belgium) were used. Sediment of this lake is known to contain a high density of $D$. magna ephippia (Rousseaux, 2011), with a high hatching success under optimal hatching conditions (Navis et al., 2013). The top 5-10 cm (active egg bank: Caceres, 1998) of the dormant egg bank was sampled in December 2012. In the winter period the egg bank has its maximum size and eggs are in diapause. Pooled sediment samples were sieved ( $1 \mathrm{~mm}$ and $250 \mu \mathrm{m}$ sieves) and stored for one year at $4{ }^{\circ} \mathrm{C}$ in the dark before ephippia were manually isolated from the sediment fraction. This storage period ensured that diapause was terminated, the eggs became quiescent and hatching could be induced under favorable conditions 


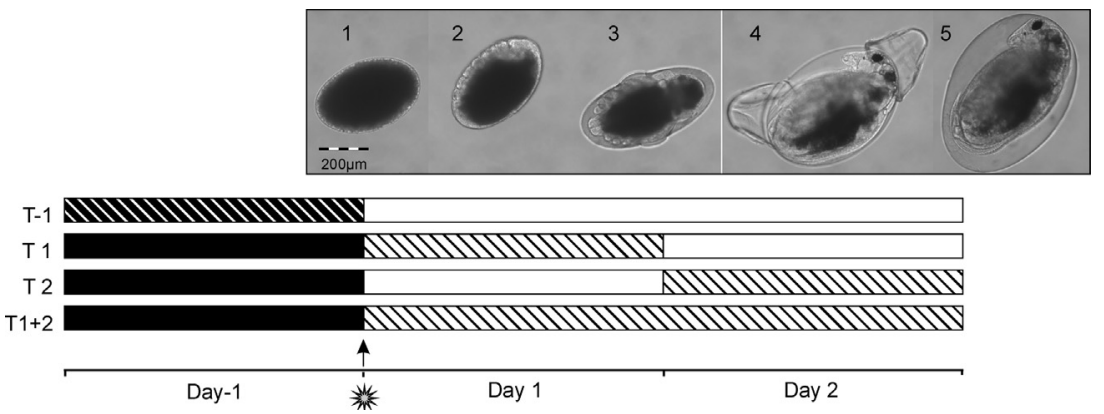

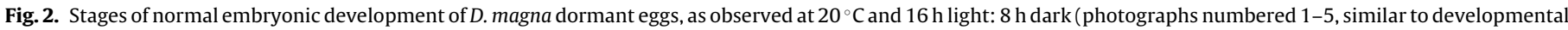

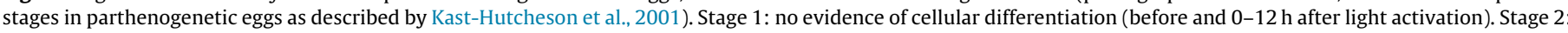

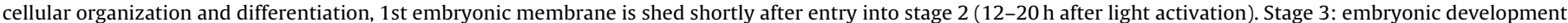

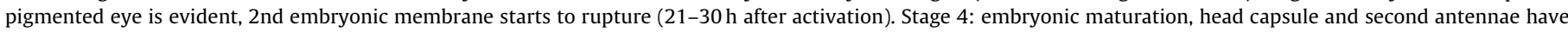

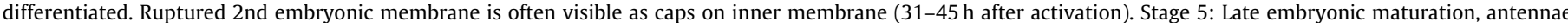

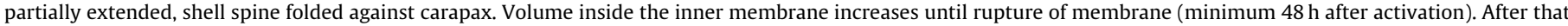

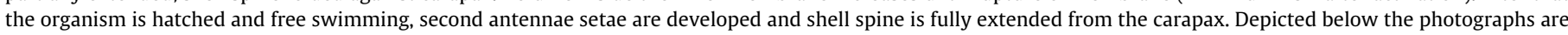

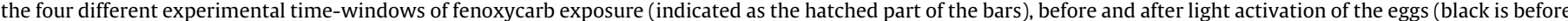

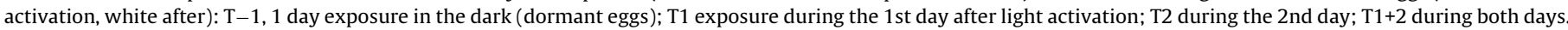

(Stross, 1971; Vandekerkhove et al., 2005). For both experiments isolated ephippia were kept under storage conditions until the start of the experiment, and all manipulations were performed in a room with only red light $(700 \mathrm{~nm})$, to prevent unwanted activation of the dormant eggs by light exposure. All eggs were thus dormant prior to incubation under optimal conditions $\left(20^{\circ} \mathrm{C}\right.$ and a photoperiod of $16 \mathrm{~h}$ light: $8 \mathrm{~h}$ dark) and hatching was induced by light activation $\left(47.2 \mu\right.$ moles $\left./ \mathrm{m}^{2} / \mathrm{s}\right)$. For certain treatments, dormant eggs were mechanically decapsulated with metal tweezers shortly before the start of the experiments and only healthy eggs were used.

\subsection{Fenoxycarb}

Fenoxycarb, a juvenile hormone mimicking insecticide, was selected as a model pesticide, because it is known to interfere with hatching success and embryonic development of D. magna parthenogenetic (Mu and Leblanc, 2004) and dormant eggs (Navis et al., 2013). Fenoxycarb (ethyl2-(4-phenoxyphenoxy)ethylcarbamate, CAS no. 72490-01-8, 99.6\% purity, Sigma-Aldrich, Germany) was dissolved in absolute ethanol (purity min. 99.8\%, VWR International, France), with a final concentration of $0.05 \%$ ethanol in all treatment solutions and in the solvent control. Test solutions were freshly prepared on each exposure day and stock solutions were stored at $-20^{\circ} \mathrm{C}$. Final nominal concentrations of 1 and $4 \mathrm{mg} / \mathrm{L}$ fenoxycarb were used. They were chosen based on previous hatching experiments (Navis et al., 2013) where these concentrations were found to delay and suppress hatching and increase the percentage of malformations in developing embryos. This enabled us to compare the sensitivity of the different embryonic developmental stages to fenoxycarb exposure. The actual concentration of the highest nominal test concentration ( $4 \mathrm{mg} / \mathrm{L}$ ) was verified using UPLC-MS/MS and corresponded to a measured concentration of $3.24 \mathrm{mg} / \mathrm{L}$ (average of four samples).

\subsection{Hatching experiment}

In a first experiment, both decapsulated (D) and encapsulated (ephippia; E) eggs (Fig. 1B) were exposed to fenoxycarb at different stages of embryonic development. Their hatching characteristics and the occurrence of developmental malformations were subsequently monitored during 10 days. Eggs were exposed to fenoxycarb during one of four exposure times: from $24 \mathrm{~h}$ before light activation until just before light activation ( $\mathrm{T}-1)$; and at different time periods after light activation: during the first $24 \mathrm{~h}$ only (T1); from $24 \mathrm{~h}$ until $48 \mathrm{~h}$ (T2); or for $48 \mathrm{~h}$, starting directly after light activation (T1+2). These exposure times coincide with different developmental stages during the hatching process of dormant eggs (Fig. 2) as observed in previous experiments (Navis et al., 2013): T1 corresponds to early embryonic development and T2 to late embryonic development. The dormant ( $\mathrm{T}-1)$ or activated ( $\mathrm{T} 1$, $\mathrm{T} 2$ and $\mathrm{T} 1+2$ ) eggs were exposed to either 1 or $4 \mathrm{mg} / \mathrm{L}$ fenoxycarb or to control conditions. This resulted in a total of 26 experimental treatments; 4 exposure times $(\mathrm{T}-1, \mathrm{~T} 1, \mathrm{~T} 2 \text { and } \mathrm{T} 1+2)^{*} 3$ pesticide concentrations $(0,1$ or $4 \mathrm{mg} / \mathrm{L}$ fenoxycarb $)+1$ solvent control for $\mathrm{T} 1+2$ (the longest exposure time) $=13$ exposure treatments* 2 egg types (D and E). For each treatment, 48 decapsulated eggs (D) or 48 ephippia (E) were placed individually in the wells of 24-well microtiter plates (polystyrene, non-coated, sterile plates, Greiner Bio-One $\mathrm{GmbH}$ ) containing $2 \mathrm{~mL}$ of exposure medium, prepared in artificial freshwater (ADaM: Klüttgen et al., 1994). To ensure that exposure to the pesticide could only occur during the predetermined time window, the eggs were rinsed and transferred into new microtiter plates with $2 \mathrm{~mL}$ fresh ADaM-water after the exposure period had ended. Treatments were randomized over plates in such a way that each treatment was allocated to four randomly assigned half multiwell plates. For treatments T1, T2 and $\mathrm{T} 1+2$, plates were incubated for 10 days at $20 \pm 2{ }^{\circ} \mathrm{C}$ in a light:dark regime of $16: 8 \mathrm{~h}$ to simulate spring conditions and induce hatching. Under these specific conditions, hatching of eggs from this population is known to be very successful (above 80\%) and synchronized (Navis et al., 2013). For treatment T-1, plates were first exposed to fenoxycarb in total darkness at $20 \pm 2{ }^{\circ} \mathrm{C}$, simulating conditions preceding the activation of dormant eggs, and transferred to light conditions after the $24 \mathrm{~h}$ of dark exposure had ended. All incubated eggs were checked daily for hatching. At the end of the experiment (day 10), all ephippia (E) were opened and checked for any remaining (unhatched) eggs. In addition, embryonic development and morphological abnormalities were monitored using a stereomicroscope (for decapsulated eggs daily during the hatching experiment, for eggs encased in ephippia only after termination of the experiment).

\subsection{Fenoxycarb in dormant egg tissue - experiment and analytical method}

In a second experiment, tissue concentrations of fenoxycarb in the developing embryos were analyzed. For this, dormant eggs of $D$. magna (either decapsulated or encapsulated eggs) were exposed to 
$4 \mathrm{mg} / \mathrm{L}$ fenoxycarb at similar exposure treatments as in the previous hatching experiment. This resulted in 8 experimental treatments; 4 exposure times $(\mathrm{T}-1, \mathrm{~T} 1, \mathrm{~T} 2$ and $\mathrm{T} 1+2) * 1$ concentration fenoxycarb $(4 \mathrm{mg} / \mathrm{L})^{*} 2$ egg types ( $\mathrm{D}$ and $\mathrm{E}$ ). For each treatment three replicates were included, and per replicate 100 eggs (D) or 100 ephippia (E) were exposed in the wells of a 6 -well microtiter plate with $6 \mathrm{~mL}$ of exposure solution. Dormant eggs were removed from the ephippia directly after the exposure period had ended and only the eggs were used for further analysis to exclude fenoxycarb retained by the ephippial case. All eggs were rinsed in fresh ADaM-water, collected into cryotubes ( 100 eggs per tube) and stored at $-80^{\circ} \mathrm{C}$ until further analysis.

To a sample consisting of 100 Daphnia eggs, $1 \mathrm{~mL}$ of pure methanol was added and the mixture was vortexed during $1 \mathrm{~min}$. After $1 \mathrm{~h}$ of equilibration, the mixture was vortexed again and subsequently centrifuged at $16,000 \times g$ (Galaxy $16 \mathrm{DH}$ ultracentrifuge, VWR, Belgium). The supernatant was $1 / 1$ diluted with water and $10 \mu \mathrm{L}$ of this solution was injected into the UPLC-MS/MS system (Waters Acquity UPLC system coupled to a Waters Xevo-TQS triple quadrupole mass spectrometer, with a Waters Acquity BEH $\mathrm{C} 18\left(1.7 \mu \mathrm{m}, 100 \mathrm{~mm}^{*} 2.1 \mathrm{~mm}\right)$ column at $\left.40^{\circ} \mathrm{C}\right)$. The mobile phase consisted of a water/acetonitrile $/ 4 \mathrm{mM}$ ammonium acetate $/ 0.1 \%$ formic acid gradient. The mass spectrometer was operated in positive electrospray mode and fenoxycarb was detected on the basis of the MRM transition 301.98 (precursor ion) $>87.8$ (product ion). The cone voltage was set at $40 \mathrm{~V}$, the collision energy at $19 \mathrm{~V}$. The peak of fenoxycarb was integrated and the concentration was calculated using external calibration. A linear correlation between peak area and concentration was obtained, with a correlation coefficient $\left(r^{2}\right)$ of $>0.995$. The average recovery was $86 \%$; the recovery was determined for eggs fortified at a concentration of $40 \mathrm{ng} / 100$ eggs. The limit of quantification, which was calculated as the concentration corresponding to 6 times the chromatogram noise of a $0.3 \mu \mathrm{g} / \mathrm{L}$ extract, was $0.02 \mathrm{ng} / 100$ eggs (or $0.02 \mu \mathrm{g} / \mathrm{L}$ in the extract).

All reagents used were analytical grade and obtained from commercial sources; methanol and acetonitrile (UHPLC-grade, Fisher, Belgium), formic acid ( $>98 \%$, Merck), fenoxycarb and ammonium acetate (resp. purity $99.5 \%$ and $99.9 \%$, Sigma-Aldrich, Belgium). Water used was purified using a Milli-Q Direct-Q3 system (Millipore, Milford, MA, USA). Individual standard solutions of fenoxycarb were prepared in methanol at concentrations of 0.09 to $34 \mu \mathrm{g} / \mathrm{L}$ and stored at $4{ }^{\circ} \mathrm{C}$.

\subsection{Statistical analysis}

For the hatching experiment, both hatching success as well as developmental malformations of the embryos (in.\%) were related to timing and concentration of fenoxycarb exposure as well as to egg type (decapsulated and encapsulated) using generalized linear models (GLM) with a logit-link function and binomial distribution, followed by sequential Bonferroni-correction (Holm, 1979), to correct for multiple testing. Plate identity was taken into account by including it as a random blocking factor. In the hatching experiment, blank controls were included for each exposure time while a solvent control treatment was incorporated for the longest fenoxycarb exposure $(\mathrm{T} 1+2)$. Effects of the pesticide on timing of hatching (day of maximum hatching) were evaluated only for decapsulated eggs, using two-way ANOVA's followed by Tukey's HSD post hoc tests. For encapsulated eggs, this was not possible, since hatched (but deformed) individuals still present in the ephippia were only observed upon opening of the ephippia after termination of the experiment, making it impossible to determine their actual day of hatching. Tissue concentrations of fenoxycarb were log transformed, in order to ensure homogeneity of variances (Levene's test) and the effect of exposure time and egg type on the concentrations in the eggs were also analyzed using two-way ANOVA's and Tukey's
Table 1

Results of generalized linear model testing effects of fenoxycarb exposure (fnx conc), window of exposure (time), egg type and their interactions, on cumulative hatching after 10 days and developmental malformations in hatched individuals.

\begin{tabular}{lrrr}
\hline & Chi $^{2}$ & Df & $p$-Value \\
\hline Cumulative hatching (\%) & & & \\
Fnx conc & 98.43 & 3 & $<0.001$ \\
Time & 21.61 & 3 & $<0.001$ \\
Egg type & 118.57 & 1 & $<0.001$ \\
Fnx conc*time & 10.08 & 6 & 0.121 \\
Fnx conc*egg type & 22.93 & 3 & $<0.001$ \\
Time*egg type & 12.97 & 3 & 0.005 \\
Fnx conc*time*egg type & 16.85 & 6 & 0.010 \\
Developmental malformations (\%) & & & \\
Fnx conc & 711.50 & 3 & $<0.001$ \\
Time & 45.43 & 3 & $<0.001$ \\
Egg type & 72.01 & 1 & 0.820 \\
Fnx conc*time & 2.91 & 6 & 0.241 \\
Fnx conc*egg type & 4.20 & 3 & 0.066 \\
Time*egg type & 7.18 & 3 & 0.278 \\
Fnx conc*time*egg type & 7.48 & 6 & \\
\hline
\end{tabular}

HSD post hoc tests. All statistical analysis were performed in R statistical software v3.0.2 (The R Foundation for Statistical Computing, 2013).

\section{Results}

\subsection{Hatching experiment}

Both fenoxycarb exposure and egg type (decapsulated vs encapsulated) had a significant effect on hatching success of $D$. magna dormant eggs (Table 1). The extent of the effects differed between the four exposure times. When exposure took place during the two days after activation (i.e. incubation under light conditions) (T1+2), or only on the second day after activation (T2), hatching success of the decapsulated eggs was significantly negatively impacted by fenoxycarb (reduction of $26.6 \%$ and $33.5 \%$ at $4 \mathrm{mg} / \mathrm{L}$ fenoxycarb for T1+2 and T2, respectively; Fig. 3 C and D). For the other two exposure times no significant effect on hatching of decapsulated eggs was observed. Hatching of encapsulated eggs was significantly negatively impacted by fenoxycarb exposure at $\mathrm{T}-1$ ( 1 day in the dark) and $\mathrm{T} 1+2$ (2 days, in light); hatching in these treatments was reduced with $37.4 \%$ and $39.7 \%$, respectively (Fig. 3 A and D).

Even in treatments where fenoxycarb had no direct effects on hatching, it caused malformations in developing embryos (deformities of tail spine, antennae, carapax and compound eye were observed). This increase in developmental malformations was significant (Table 1) at all four exposure times and both fenoxycarb concentrations (Fig. 3E-H). Malformations in embryos from decapsulated eggs were most severe when exposed at $\mathrm{T} 2$ and $\mathrm{T} 1+2$. At these two exposure times hatching was also significantly delayed (Fig. 4). The percentage of developmental malformations was lowest in encapsulated eggs exposed at T-1; many eggs (55-59\%) from this treatment did not develop at all and remained in stage 1 . Most deformed embryos exposed at $\mathrm{T}-1$ and $\mathrm{T} 1$ could still hatch, but at $\mathrm{T} 2$ and $\mathrm{T} 1+2$ there was a large fraction of deformed embryos that were unable to hatch ( $40.4 \%$ and $27.1 \%$ resp. for decapsulated eggs at $4 \mathrm{mg} / \mathrm{L}$ fenoxycarb).

\subsection{Fenoxycarb concentration in eggs}

Concentrations measured in the eggs ranged from 15.7 to $1337.3 \mathrm{ng} / 100$ eggs (Fig. 5). The concentrations of fenoxycarb differed significantly among the exposure times $(F=89.664 ; \mathrm{df}=3$; $p<0.001)$, but not between the two egg types $(F=0.824 ; \mathrm{df}=1$; $p=0.377$ ). Lowest concentrations were detected in dormant eggs 

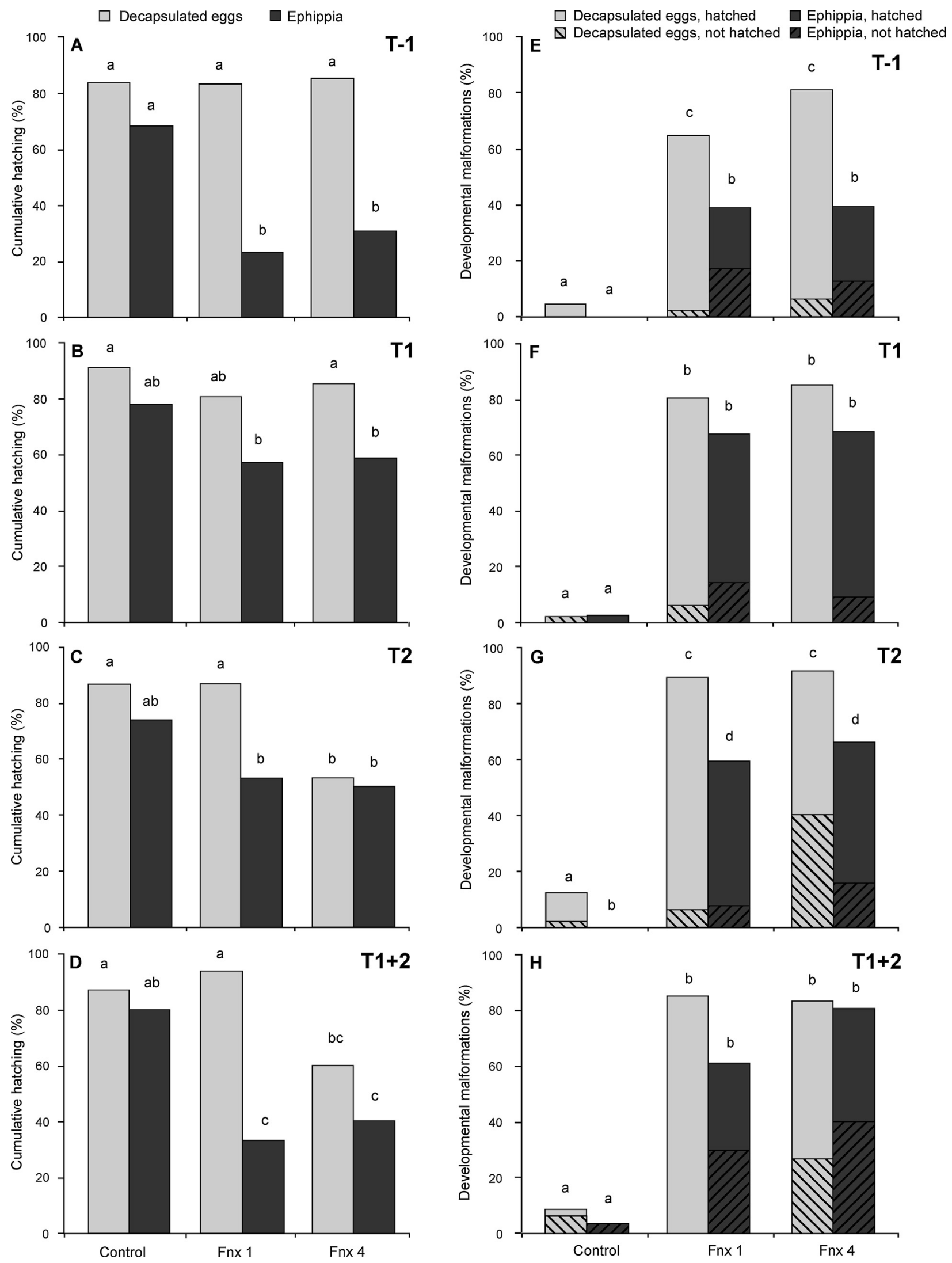

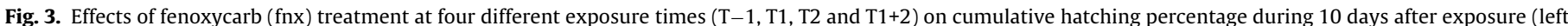

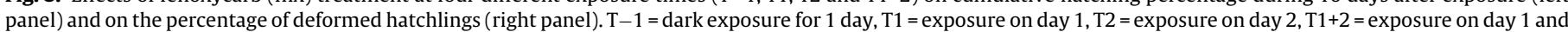

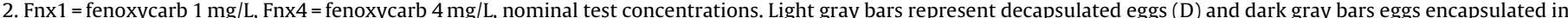

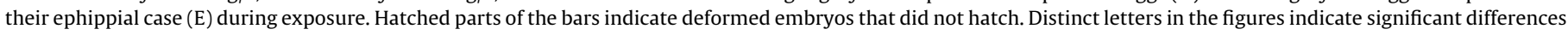
among treatments within exposure times ( $n=48, p \leq 0.05$, generalized linear model, followed by sequential Bonferroni-correction). 


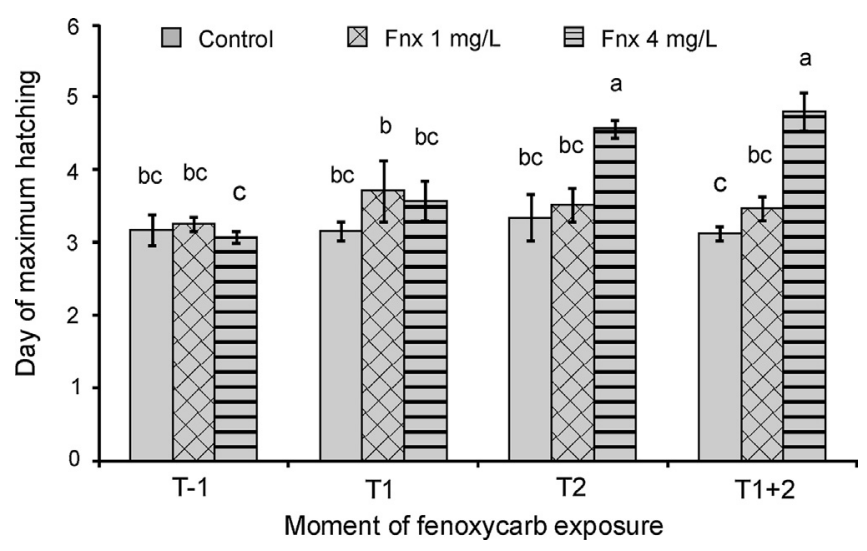

Fig. 4. Effects of fenoxycarb (Fnx) exposure on day of maximum hatching, for the four different exposure times $(\mathrm{T}-1, \mathrm{~T} 1, \mathrm{~T} 2, \mathrm{~T} 1+2)$ and for decapsulated eggs only. At $\mathrm{T} 2$ and $\mathrm{T} 1+2$ hatching was significantly delayed at the highest fenoxycarb concentration $(4 \mathrm{mg} / \mathrm{L})$. Distinct letters in the figure indicate significant differences $(n=12$, $p \leq 0.05,2$-way ANOVA, followed by Tukey's HSD post hoc test).

that were encapsulated in their ephippium during exposure to fenoxycarb for 1 day while still in the dark ( $\mathrm{T}-1)$. Highest concentrations were detected in decapsulated eggs, exposed during the 2nd day after activation by light (T2) (Fig. 5). Average concentrations (mean of three replicates) for these treatments were; $19.6 \mathrm{ng} / 100$ eggs for encapsulated eggs from $\mathrm{T}-1$ and $923.2 \mathrm{ng} / 100$ eggs for decapsulated eggs from $\mathrm{T} 2$.

In Fig. 6, we integrated the results of hatching success and intra egg pesticide concentrations. For decapsulated eggs, treatments with the highest tissue concentration of fenoxycarb coincided with lowest hatching success (Fig. 6A). Even at low tissue concentrations, fenoxycarb caused developmental malformations in the embryos (Fig. 6B). And in all treatments a very large portion (>80\%) of the hatchlings was deformed (Fig. 6C).

\section{Discussion}

Although $D$. magna is a key species in many freshwater ecosystems (Lampert and Kinne, 2011; Miner et al., 2012) and one of the most commonly used test species in ecotoxicology (Walker, 2014), very little is known about the effects of chemicals on their dormant

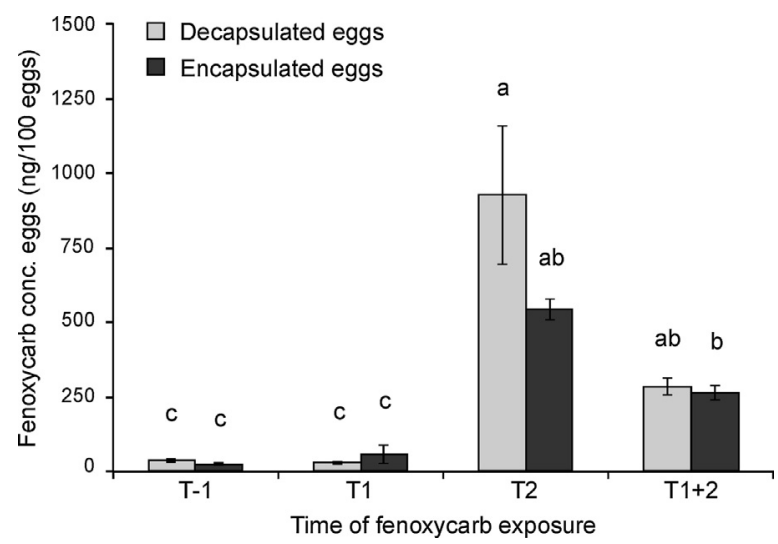

Fig. 5. Concentrations of fenoxycarb measured by UPLC-MS/MS in D. magna dormant eggs; light gray bars indicate decapsulated eggs, dark gray bars represent eggs encapsulated in their ephippial case during exposure. The two egg types were exposed to $4 \mathrm{mg} / \mathrm{L}$ fenoxycarb at four different stages during embryonic development $(\mathrm{T}-1, \mathrm{~T} 1, \mathrm{~T} 2$ and $\mathrm{T} 1+2)$. Highest fenoxycarb concentrations were detected in embryos exposed during later developmental stages (T2). Distinct letters in the figure indicate significant differences $(n=8, p \leq 0.05,2$-way ANOVA, followed by Tukey's HSD post hoc test).
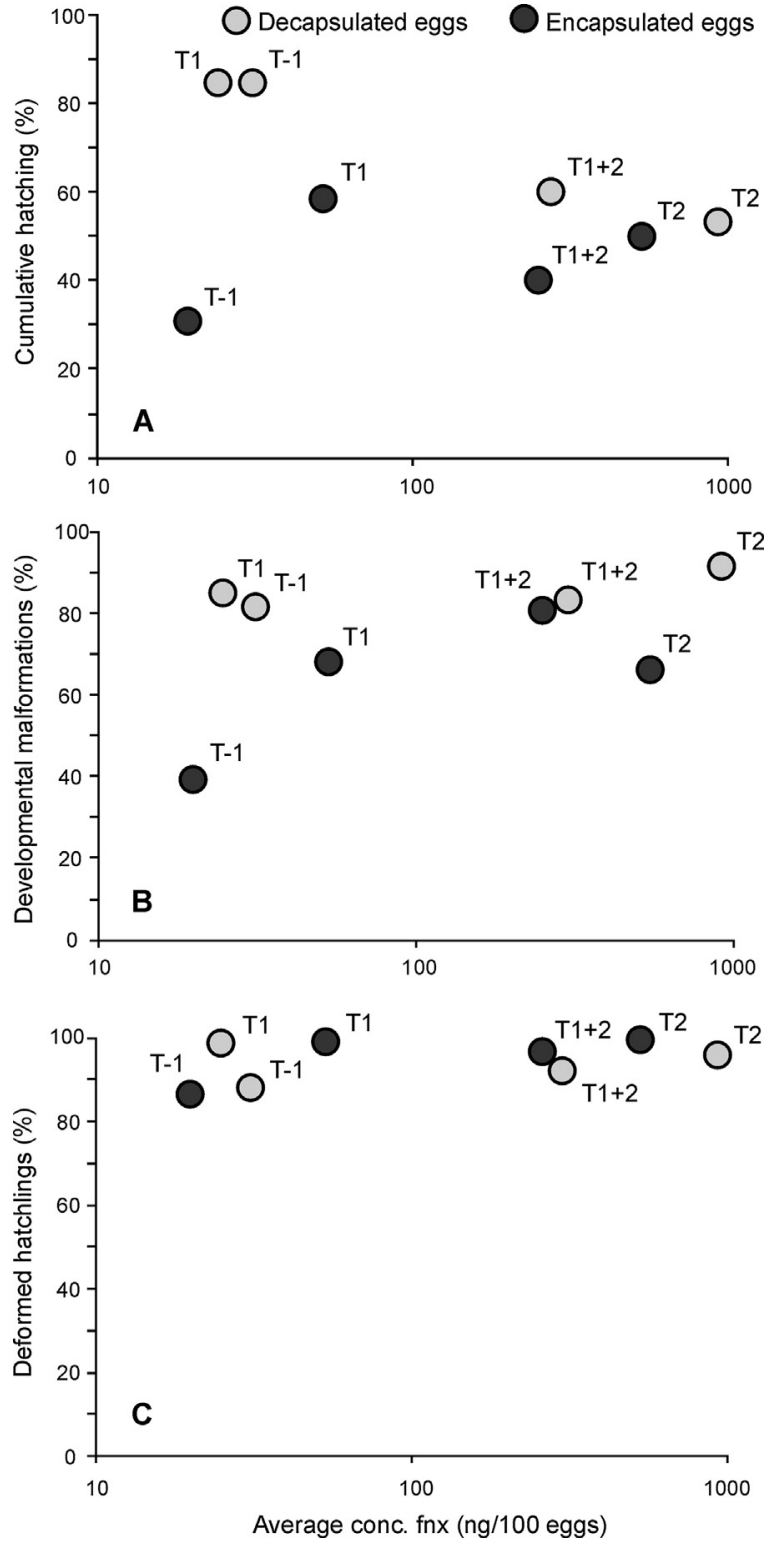

Fig. 6. Correlation between concentrations of fenoxycarb measured in egg tissue (average fenoxycarb concentration of three replicate samples, expressed in ng/100 eggs) and (A) cumulative hatching success (\%), (B) developmental malformations (\%) observed in the embryos, and (C) deformed hatchlings (\%). Light gray circles represent treatments with decapsulated eggs, dark gray circles with encapsulated eggs, exposure times $(\mathrm{T}-1, \mathrm{~T} 1, \mathrm{~T} 2$ and $\mathrm{T} 1+2)$ are indicated next to the corresponding symbols.

life stages. In previous work we have demonstrated that pesticides can not only affect development and hatching success of $D$. magna dormant eggs, but also survival and performance of the individuals hatched from exposed eggs (Navis et al., 2013). In the present study, building further on these findings, we have shown that, (a) the time-window of exposure during embryonic development determines the impact on hatching success and timing as well as the severity of deformations in embryos and hatchlings, and (b) these effects can be related to the internal fenoxycarb concentrations as measured in the egg tissue. In addition, fenoxycarb tissue concentrations in decapsulated versus encapsulated eggs did not differ significantly, suggesting that the ephippial case offers limited or no direct protection against fenoxycarb exposure. 


\subsection{Timing of exposure determines impact of fenoxycarb on developing embryos}

As hypothesized, the negative effects of fenoxycarb on embryonic development and hatching characteristics (cumulative percentage and timing) of $D$. magna dormant eggs, differed significantly between the four exposure times. The final stages of embryonic development (Fig. 2 Stages 4 and 5) were most sensitive to fenoxycarb exposure. Before light activation, dormant eggs are surrounded by three membranes (Zaffagnini, 1987), after activation and during embryonic development these membranes are shed and at the last developmental stage, embryos are only protected by one external membrane and become much more active. This allows a higher influx of the surrounding medium (Davison, 1969) and thus also fenoxycarb into the eggs. Bodar et al. (1989) similarly found that the last embryonic instars of developing parthenogenetic eggs of $D$. magna were most sensitive to metal exposure.

\subsection{Bioconcentration of fenoxycarb in dormant egg tissue}

Previously, we have shown that the extent to which pesticides can affect dormant eggs of $D$. magna can differ between pesticides (Navis et al., 2013): fenoxycarb had significant negative effects on development and hatching, while there were no such direct effects of carbaryl. We suggested that this could be related to the mode of action of the toxicant and difference in the ability of the two pesticides to bioconcentrate in the eggs. In this study we have proven that fenoxycarb is indeed taken up from the water fraction by dormant eggs of $D$. magna and that the level of bioconcentration depends on the timing of pesticide exposure during embryonic development. Fenoxycarb levels in eggs exposed before light activation ( $\mathrm{T}-1)$ or during the first developmental stages (T1) were relatively low, while higher concentrations were observed when exposure took place during later embryonic development (T2 and $\mathrm{T} 1+2)$.

Our findings on bioconcentration of fenoxycarb cannot directly be compared to other studies, since, to our best knowledge, this is the first study to quantify pesticide concentrations inside Daphnia dormant eggs. In two previous studies, metals (Wyn et al., 2007) and several organic contaminants (Chiaia-Hernandez et al., 2013) were measured in whole Daphnia ephippia (including the eggs as well as the protective maternal case) while in a diapausing state. Both studies found that contaminants were taken up in ephippia. Bioconcentration of organic compounds depended mainly on their hydrophobicity. For diazinon, a pesticide with a similar $\log K_{\text {ow }}$ as fenoxycarb (but a different mode of action), a bioconcentration factor of $170 \mathrm{~L} / \mathrm{kg}_{\text {lip }}$ has been reported (Chiaia-Hernandez et al., 2013). However, a substantial number of ephippia in this study did not contain any eggs (around 80\%). Therefore it is likely that part of the toxicant levels measured, actually consisted of chemicals retained/absorbed by the ephippial case, instead of the egg tissue.

\subsection{Protective value of ephippial case}

One of our aims was to identify whether the ephippial envelope would protect the dormant eggs against toxicant exposure. Tissue concentrations did not differ significantly between decapsulated versus encapsulated eggs at any of the four exposure windows. This observation suggests limited or no direct protection of the ephippial case against chemical exposure of the embryos. Instead, the effect of the pesticide exposure seems to be determined by the (number of) membranes surrounding the embryo during the exposure period.

In addition, fenoxycarb had an even stronger effect on hatching success of encapsulated than decapsulated eggs (Fig. 3A-D). A possible explanation for this might be that embryos from encapsulated eggs needed more energy to hatch (extra cost of getting out of the ephippial case), leading to a stronger negative effect of pesticide exposure.

\subsection{Ecological implications}

With this study we contribute to existing evidence showing that pollutants not only affect survival and reproduction of clonal lineages of Daphnia, but also have effects on hatching of dormant eggs (Angeler et al., 2006; Raikow et al., 2006, 2007; Alekseev et al., 2010; Navis et al., 2013). Even though dormant eggs show a high tolerance to extreme physical conditions like freezing and desiccation (Mellors, 1975; Radzikowski, 2013), they can still be affected by chemical pollution. Effect levels of fenoxycarb for development and hatching are about twice the acute effect levels for neonates: $48 \mathrm{~h} \mathrm{EC}_{50}$ of D. magna neonates is $0.5-0.6 \mathrm{mg} / \mathrm{L}$ (EFSA, 2010), while the $\mathrm{EC}_{50}$ for hatching is $1.3 \mathrm{mg} / \mathrm{L}$ (Navis et al., 2013). Embryonic development of parthenogenetic eggs seems to be affected at concentrations about 1000 times lower (Mu and Leblanc, 2004) than embryonic development in dormant eggs. This indicates that, with respect to fenoxycarb exposure, dormant eggs are less sensitive than endpoints related to the asexual part of the reproduction cycle in D. magna. Our study clearly indicates that the severity of the effects of pesticide exposure on developing dormant eggs of $D$. magna depends on the timing of exposure, with the later developmental stages being most sensitive. However, eggs were not only affected during embryonic development (after activation by light incubation), but even when they were still dormant (in dark conditions) and when surrounded by an ephippial case. Depending on the reversibility of these effects, exposure to certain types of chemicals could therefore impact the size and structure of zooplankton dormant egg banks, in turn affecting the benthic-pelagic coupling in aquatic systems (Gyllström and Hansson, 2004; Angeler and Garcia, 2005). Interference with development and hence a reduced hatching from the mixed egg bank may have effects on (re)colonization of aquatic systems. Small active population sizes could further lower the amount of produced dormant stages, eroding the buffering capacity of the egg bank against the risk of local extinction and loss of genetic diversity (Levin, 1990; Brendonck and De Meester, 2003). In current higher-tier studies concerning potential longterm impacts of chemical exposure on zooplankton communities and populations, impacts on dormant life stages are generally not taken into account (e.g. Beketov et al., 2008; Stampfli et al., 2011). This could result in incomplete or false assessments regarding the potential for recovery of aquatic ecosystems that were previously exposed to pesticides. Our results stress the importance of considering the full life-cycle of model organisms used in ecotoxicological studies, that are ultimately aimed at assessing risks of chemical exposure on natural aquatic ecosystems.

\section{Acknowledgements}

This research was funded by a Ph.D. grant of the Institute for the Promotion of Innovation through Science and Technology in Flanders (IWT Vlaanderen) and the KU Leuven Research Fund (Excellence Center Financing PF/2010/07). The authors would like to thank Camille De Raedemaeker and Ruben Cardoen for their practical assistance during the laboratory experiments.

\section{References}

Alekseev, V., Lampert, W., 2001. Maternal control of resting-egg production in Daph nia. Nature 414, 899-901.

Alekseev, V., Makrushin, A., Hwang, J.-S., 2010. Does the survivorship of activated resting stages in toxic environments provide cues for ballast water treatment? Mar. Pollut. Bull. 61, 254-258. 
Angeler, D., Sanchez, B., Garcia, G., Moreno, J., 2006. Community ecotoxicology: invertebrate emergence from Fire Trol 934 contaminated vernal pool and salt marsh sediments under contrasting photoperiod and temperature regimes. Aquat. Toxicol. 78, 167-175.

Angeler, D.G., Garcia, G., 2005. Using emergence from soil propagule banks as indicators of ecological integrity in wetlands: advantages and limitations. J. N. Am. Benthol. Soc. 24, 740-752.

Beketov, M.A., Schäfer, R.B., Marwitz, A., Paschke, A., Liess, M., 2008. Long-term stream invertebrate community alterations induced by the insecticide thiacloprid: effect concentrations and recovery dynamics. Sci. Total Environ. 405 96-108.

Bodar, C.W.M., Zee, A.V.D., Voogt, P.A., Wynne, H., Zandee, D.I., 1989. Toxicity of heavy metals to early life stages of Daphnia magna. Ecotoxicol. Environ. Saf. 17, 333-338.

Brendonck, L., De Meester, L., 2003. Egg banks in freshwater zooplankton: evolutionary and ecological archives in the sediment. Hydrobiologia 491, 65-84

Bulmer, M.G., 1982. Cyclical parthenogenesis and the cost of sex. J. Theor. Biol. 94, 197-207.

Caceres, C.E., 1997. Temporal variation, dormancy, and coexistence: a field test of the storage effect. Proc. Natl. Acad. Sci. U. S. A. 94, 9171-9175.

Caceres, C.E., 1998. Interspecific variation in the abundance, production and emergence of Daphnia diapausing eggs. Ecology 79, 1699-1710.

Chiaia-Hernandez, A.C., Ashauer, R., Moest, M., Hollingshaus, T., Jeon, J., Spaak, P., Hollender, J., 2013. Bioconcentration of organic contaminants in Daphnia resting eggs. Environ. Sci. Technol. 47, 10667-10675.

Davison, J., 1969. Activation of the ephippial egg of Daphnia pulex. J. Gen. Physiol. 53, 562-575

De Meester, L., Gomez, A., Simon, J., 2004. Evolutionary and ecological genetics of cyclical parthenogens. In: Evolution: From Molecules to Ecosystems. Oxford University Press, pp. 122-134.

De Meester, L., Vanoverbeke, J., De Gelas, K., Ortells, R., Spaak, P., 2006. Genetic structure of cyclic parthenogenetic zooplankton populations - a conceptual framework. Arch. Hydrobiol. 167, 217-244.

Decaestecker, E., Meester, L., Mergeay, J., 2009. Cyclical parthenogenesis in Daphnia: sexual versus asexual reproduction. In: Lost Sex., pp. 295-316.

Dodson, S.I., Merritt, C.M., Shannahan, J.-P., Shults, C.M., 1999. Low exposure concentrations of atrazine increase male production in Daphnia pulicaria. Environ. Toxicol. Chem. 18, 1568-1573.

Ebert, D., 2005. Ecology, Epidemiology, and Evolution of Parasitism in Daphnia. National Library of Medicine (US), National Center for Biotechnology Information, Bethesda, MD.

EFSA, 2010. Conclusion on the peer review of the pesticide risk assessment of the active substance fenoxycarb. EFSA J. 8, 75

Frisch, D., Morton, P.K., Chowdhury, P.R., Culver, B.W., Colbourne, J.K., Weider, L.J., Jeyasingh, P.D., 2014. A millennial-scale chronicle of evolutionary responses to cultural eutrophication in Daphnia. Ecol. Lett. 17, 360-368.

Gyllström, M., Hansson, L.-A., 2004. Dormancy in freshwater zooplankton: induction, termination and the importance of benthic-pelagic coupling. Aquat. Sci. 66, 274-295.

Holm, S., 1979. A simple sequentially rejective multiple test procedure. Scand. J. Stat. 6, 65-70.

Kast-Hutcheson, K., Rider, C.V., LeBlanc, G.A., 2001. The fungicide propiconazole interferes with embryonic development of the crustacean Daphnia magna. Environ. Toxicol. Chem. 20, 502-509.

Klüttgen, B., Dülmer, U., Engels, M., Ratte, H.T., 1994. ADaM, an artificial freshwate for the culture of zooplankton. Water Res. 28, 743-746.

Koch, U., Elert, E., Straile, D., 2009. Food quality triggers the reproductive mode in the cyclical parthenogen Daphnia (Cladocera). Oecologia 159, 317-324.

Lampert, W., Kinne, O., 2011. Daphnia: Development of a Model Organism in Ecology and Evolution. International Ecology Institute.

Levin, D.A., 1990. The seed bank as a source of genetic novelty in plants. Am. Nat. $135,563-572$.

Mellors, W.K., 1975. Selective predation of ephippal Daphnia and the resistance of ephippal eggs to digestion. Ecology 56, 974-980.
Miner, B.E., De Meester, L., Pfrender, M.E., Lampert, W., Hairston, N.G., 2012. Linking genes to communities and ecosystems: Daphnia as an ecogenomic model. Proc. R. Soc. B: Biol. Sci. 279, 1873-1882

$\mathrm{Mu}, \mathrm{X}$., Leblanc, G.A., 2004. Synergistic interaction of endocrine-disrupting chemicals: model development using an ecdysone receptor antagonist and a hormone synthesis inhibitor. Environ. Toxicol. Chem. 23, 1085-1091.

Navis, S., Waterkeyn, A., Voet, T., De Meester, L., Brendonck, L., 2013. Pesticide exposure impacts not only hatching of dormant eggs, but also hatchling survival and performance in the water flea Daphnia magna. Ecotoxicology 22 803-814.

OECD 2004. OECD Guidelines for the Testing of Chemicals. Test No. 202: Daphnia sp. Acute Immobilisation Test. Organisation for Economic Co-operation and Development, pp. 12.

OECD, 2012. OECD Guidelines for the Testing of Chemicals. Test No. 211: Daphnia magna Reproduction Test. Organisation for Economic Co-operation and Development, pp. 25.

Olmstead, A.W., LeBlanc, G.A., 2001. Temporal and quantitative changes in sexua reproductive cycling of the cladoceran Daphnia magna by a juvenile hormone analog. J. Exp. Zool. 290, 148-155

Olmstead, A.W., LeBlanc, G.A., 2003. Insecticidal juvenile hormone analogs stimulate the production of male offspring in the crustacean Daphnia magna. Environ. Health Perspect. 111, 919-924.

Palma, P., Palma, V.L., Matos, C., Fernandes, R.M., Bohn, A., Soares, A.M.V.M., Barbosa, I.R., 2009. Assessment of the pesticides atrazine, endosulfan sulphate and chlorpyrifos for juvenoid-related endocrine activity using Daphnia magna. Chemosphere 76, 335-340.

Radzikowski, J., 2013. Resistance of dormant stages of planktonic invertebrates to adverse environmental conditions. J. Plankton Res. 35, 707-723.

Raikow, D.F., Landrum, P.F., Reid, D.F., 2007. Aquatic invertebrate resting egg sensitivity to glutaraldehyde and sodium hypochlorite. Environ. Toxicol. Chem. 26, 1770-1773.

Raikow, D.F., Reid, D.F., Maynard, E.E., Landrum, P.F., 2006. Sensitivity of aquatic invertebrate resting eggs to SeaKleen (menadione): a test of potential ballast tank treatment options. Environ. Toxicol. Chem. 25, 552-559.

Rousseaux, S., (PhD dissertation) 2011. The Importance of Genetic Diversity and Evolution in Metacommunities. Katholieke Universiteit Leuven, Leuven.

Schultz, T.W., 1977. Fine structure of the ephippium in Daphnia pulex (Crustacea: Cladocera). Trans. Am. Microsc. Soc. 96, 313-321.

Seidman, L.A., Larsen, J.H., 1979. Ultrastructure of the envelopes of resistant and nonresistant Daphnia eggs. Can. J. Zool. 57, 1773-1777.

Shurin, J.B., Dodson, S.I., 1997. Sublethal toxic effects of cyanobacteria and nonylphenol on environmental sex determination and development in Daphnia. Environ. Toxicol. Chem. 16, 1269-1276.

Slusarczyk, M., Dawidowicz, P., Rygielska, E., 2005. Hide, rest or die: a light-mediated diapause response in Daphnia magna to the threat of fish predation. Freshw. Biol. 50, 141-146.

Stampfli, N.C., Knillmann, S., Liess, M., Beketov, M.A., 2011. Environmental context determines community sensitivity of freshwater zooplankton to a pesticide. Aquat. Toxicol. 104, 116-120.

Stross, R.G., 1971. Photoperiod control of diapause in Daphnia IV. Light and $\mathrm{CO}_{2}$-sensitive phases within the cycle of activation. Biol. Bull. 140, $137-155$.

Tatarazako, N., Oda, S., 2007. The water flea Daphnia magna (Crustacea, Cladocera) as a test species for screening and evaluation of chemicals with endocrine disrupting effects on crustaceans. Ecotoxicology 16, 197-203.

Vandekerkhove, J., Declerck, S., Brendonck, L., Conde-Porcuna, J.M., 2005. Hatching of cladoceran resting eggs: temperature and photoperiod. Freshw. Biol. 50, 96-104.

Walker, C.H., 2014. Ecotoxicology: Effects of Pollutants on the Natural Environment. CRC Press.

Wyn, B., Sweetman, J.N., Laevitt, P.R., Donald, D.B., 2007. Historical metal concentrations in lacustrine food webs revealed using fossil ephippia from Daphnia. Ecol. Appl. 17, 754-764.

Zaffagnini, F., 1987. In: Peters, R.H., De Bernardi, R. (Eds.), Reproduction in Daphnia., pp. 245-284, Daphnia. 